\title{
Formation and Evolution Mechanisms of Severe Haze Pollution in the Sichuan Basin, Southwest China
}

\author{
Xianyu Yang ${ }^{1}$, Yaqiong $\mathrm{Lu}^{2 *}$, Xinsheng $\mathrm{Zhu}^{3^{*}}$, Jianjun $\mathrm{He}^{4}$, Qi Jiang ${ }^{5}$, Kai Wu ${ }^{1,6}$, Haolin Wang ${ }^{7}$, \\ Xiaoling Zhang', Shigong Wang ${ }^{1}$
}

\author{
${ }^{1}$ Plateau Atmosphere and Environment Key Laboratory of Sichuan Province, School of Atmospheric Sciences, Chengdu \\ University of Information Technology, Chengdu, China \\ ${ }^{2}$ Institute of Mountain Hazards and Environment, Chinese Academy of Sciences, Chengdu, China \\ ${ }^{3}$ Nanjing Institute of Environmental Science, Nanjing, China \\ ${ }^{4}$ State Key Laboratory of Severe Weather and Key Laboratory of Atmospheric Chemistry of CMA, Chinese Academy of \\ Meteorological Sciences, Beijing, China \\ ${ }^{5}$ Huangpi Meteorological Bureau of Wuhan, Wuhan, China \\ ${ }^{6}$ Department of Land, Air, and Water Resources, University of California, Davis, CA, USA \\ ${ }^{7}$ School of Atmospheric Sciences, Sun Yat-sen University, Zhuhai, Guangdong, China
}

\begin{abstract}
Severe haze episodes are important environmental issues, and the rapid formation and evolution mechanisms of such episodes over complex terrain remain poorly understood. The Sichuan Basin (SCB) periodically experienced heavy haze pollution during the winter of 2016 , with the maximum regional average $\mathrm{PM}_{2.5}$ concentration reaching almost $120 \mu \mathrm{g} \mathrm{m}^{-3}$. In this study, we characterize a severe haze episode in the SCB from 20 to 30 January 2017 using comprehensive measurements and model analyses. The evolution of this severe episode shows clear stages, with gradual $\mathrm{PM}_{2.5}$ increases under stagnant weather conditions in Stage I (aerosol accumulation stage) and with explosive $\mathrm{PM}_{2.5}$ increases mainly associated with cross-border transport from the southern SCB in Stage III (rapid formation stage). The process analysis results indicated that primary emissions and aerosol processes were the major sources of $\mathrm{PM}_{2.5}$ in these urban regions, whereas vertical transport and dry deposition generally acted as sinks of $\mathrm{PM}_{2.5}$. In the presence of southwesterly synoptic winds, the aerosols emitted from the southern SCB were transported to Chengdu and the surrounding areas through horizontal transport and accounted for $66 \%$ of the $\mathrm{PM}_{2.5}$ concentration in Chengdu during Stage III. Our results reveal the detailed formation mechanism of a severe haze episode in the SCB under the effects of regional transport and synoptic forcing patterns to improve the understanding of haze formation in areas with complex terrain.
\end{abstract}

Keywords: Air quality; Haze pollution; Process analysis; Sichuan Basin.

\section{INTRODUCTION}

Due to rapid economic development and the acceleration of urbanization in China, regional haze pollution characterized by high fine particle $\left(\mathrm{PM}_{2.5}\right)$ concentrations has become a serious environmental issue (Chan and Yao, 2008; Lei et al., 2011). To mitigate haze pollution, the "Air Pollution Prevention and Control Action Plan (APPCAP)" and the "National Ten Measures" were implemented by the Chinese State Council in 2013 to improve the air quality in China. Although the control measures have been generally successful,

\footnotetext{
* Corresponding authors.

E-mail address: yaqiong@imde.ac.cn (Y. Lu); zxs_dream@yeah.net (X. Zhu)
}

large challenges remain, especially regarding the formation and evolution mechanisms of episodes of continuously high $\mathrm{PM}_{2.5}$, which are poorly understood (Zheng et al., 2015; Li et al., 2017;).

Because of serious haze pollution resulting from high anthropogenic emissions and unfavorable meteorological conditions, the Sichuan Basin (SCB) has become one of the most polluted city clusters in China over the last few years (Zhao et al., 2018). Extensive studies have been conducted to explore the source and formation of haze pollution in the SCB (Tian et al., 2017; Qiao et al., 2019a). Based on the National Centers for Environmental Prediction (NCEP) reanalysis data and clustering analysis method, Sun et al. (2020) classified the circulation patterns during periods of continuous pollution in the SCB and found that a weak highpressure system located in the SCB could enhance pollution by suppressing the planetary boundary layer height (PBLH). 
By analyzing the chemical composition of $\mathrm{PM}_{2.5}$, Song et al. (2019) reported that the secondary conversion of $\mathrm{SO}_{2}, \mathrm{NO}_{x}$ and nonmethane hydrocarbons (NMHCs) to sulfate, nitrate and secondary organic aerosols (SOAs), respectively, made significant contributions to persistent haze episodes in the SCB. The meteorological conditions in the SCB during winter are characterized by high relative humidity and low temperature, which favor the hygroscopic growth of fine particles and accelerate secondary transformations from gaseous precursors to inorganic ions (Kong et al., 2020). Additionally, the complex basin topography of this region was found to increase the accumulation of $\mathrm{PM}_{2.5}$ and intensify haze formation by reducing the wind speed and increasing the relative humidity (Zhang et al., 2019). Several studies employed the CTM model to investigate the sources of $\mathrm{PM}_{2.5}$. Zhang et al. (2016) utilized HJ-1 satellite data and simulation results from the WRF-Chem model to explore the formation of a haze event and found that low mean ventilation coefficients and decrease in PBLH were conducive to the occurrence of severe haze events. Using a source-oriented version of the Community Multiscale Air Quality (CMAQ) model, Qiao et al. (2019b) quantified the relative contributions from regions inside the SCB to the $\mathrm{PM}_{2.5}$ concentration; they concluded that the transport of secondary inorganic aerosols (SIAs) and their precursors made significant contributions to haze pollution during the winter. However, previous studies focused on only monitored air pollutants, and the formation and evolution mechanisms of severe haze pollution in the SCB remain unclear. Consequently, thorough investigations involving the quantitative assessment of contributions from local emissions and regional transport to severe haze episodes are urgently needed (Chen et al., 2014; Luo et al., 2020).

In the present study, we integrate comprehensive monitoring data and the Weather Research and Forecasting-Community Multiscale Air Quality (WRF-CMAQ) modeling system to investigate the sources and formation mechanisms of an extreme regional haze episode in the SCB during the winter of 2016. The paper is organized as follows. In Sect. 2, the model configuration is described. In Sect. 3, the model performance is evaluated by comparison with observations. The formation and evolution mechanisms of the severe haze pollution are presented in Sect. 4 . The conclusions are given in Sect. 5.

\section{METHODS}

\section{Observational Data}

The simulated meteorological parameters, including temperature, relative humidity, wind speed (WS) and wind direction, are compared with hourly observation data recorded at four typical national standard basic weather stations (Chengdu, Meishan, Ziyang and Neijiang), which were obtained from the China Meteorological Data Service Center (http://data.cma.cn/en). The hourly observed surface $\mathrm{PM}_{2.5}$ concentrations over the SCB were collected from the China National Urban Air Quality Real-time Publishing Platform (http://113.108.142.147:20035/). The hourly mass concentrations of $\mathrm{SO}_{4}{ }^{2-}, \mathrm{NO}_{3}{ }^{-}, \mathrm{NH}_{4}{ }^{+}$, black carbon (BC), elemental carbon (EC) and organic carbon (OC) were determined from samples collected on the roof of the Chengdu Environmental Science Research Institute (approximately $25 \mathrm{~m}$ above the ground) in Qingyang District, Chengdu $\left(30^{\circ} 56^{\prime} \mathrm{N}, 104^{\circ} 05^{\prime} \mathrm{E}\right)$, from 1 to 31 January 2017 . This site (referenced as the CDAES site below) is a typical urban site that is close to the mixed commercial and residential area of Chengdu Second Ring Road (Fig. S1). At this sampling site, an in-situ gas and aerosol composition monitor (IGAC/S611) was used to measure the water-soluble ions $\left(\mathrm{SO}_{4}{ }^{2-}\right.$, $\mathrm{NO}_{3}{ }^{-}$, and $\mathrm{NH}_{4}{ }^{+}$) in $\mathrm{PM}_{2.5}$ on an hourly basis. Previous studies have verified the accuracy of such monitoring through comparison with the commonly used annular denuder system, and the results showed good agreement (Young et al., 2016; Tao et al., 2018). Hourly concentrations of OC and $\mathrm{EC}$ in $\mathrm{PM}_{2.5}$ were monitored using a Sunset Laboratory Model-4 OC-EC field analyzer with detection limits of $0.4 \mu \mathrm{g} \mathrm{C} \mathrm{m}^{-3}$ for OC and $0.2 \mu \mathrm{g} \mathrm{C} \mathrm{m}^{-3}$ for EC. The organic matter $(\mathrm{OM})$ content was calculated by multiplying the $\mathrm{OC}$ content by a factor of 1.4. The hourly concentration of $\mathrm{BC}$ in $\mathrm{PM}_{2.5}$ was monitored at a wavelength of $670 \mathrm{~nm}$ using a 5012 multiangle absorption photometer (MAAP, Thermo Fisher Corporation). Additional details were described in previous field studies (Song et al., 2018; Yang et al., 2020).

\section{WRF-CMAQ Simulation}

The Weather Research and Forecasting (WRF, version 3.9.1) model was applied to simulate meteorological fields, and CMAQ v5.2.1 was utilized to simulate air pollutants in the SCB during winter. The simulation period started on 15 January 2017 and ended on 31 January 2017. The first 5 days were discarded to account for spin-up and not included in the analysis. Fig. S2 illustrates the triple-nested domain with horizontal resolutions of $27 \mathrm{~km}, 9 \mathrm{~km}$ and $3 \mathrm{~km}$. The outer domain covers all of East Asia, and the inner domain covers the SCB, as shown in Fig. 1. Here, we analyzed only the inner domain to minimize the bias from lateral boundary conditions. The vertical dimension had a resolution of 30 sigma layers.

The meteorological inputs for the WRF simulations were obtained from the NCEP Final $(\mathrm{FNL}) 1.0^{\circ} \times 1.0^{\circ}$ reanalysis data (http://dss.ucar.edu/datasets/ds083.2/). To improve the model performance, analysis nudging and observation nudging were adopted, and four-dimensional data assimilation (FDDA) data were obtained from the NCEP Automated Data Processing (ADP) Operational Global Surface (ds461.0) and Upper (ds351.0) Observations. The state variables for the water-vapor mixing ratio, potential temperature, and wind were nudged with strengths of $1 \times 10^{-5}, 5 \times 10^{-5}$, and $5 \times 10^{-5} \mathrm{~s}^{-1}$, respectively (Wu et al., 2020; Xing et al., 2017). The initial and boundary conditions for the CMAQ simulation were obtained from the MOZART-4 global chemical transport model (Emmons et al., 2010). We obtained the anthropogenic emissions of air pollutants, with a grid resolution of $0.25^{\circ} \times$ $0.25^{\circ}$, from the Multiresolution Emission Inventory for China (MEIC) in 2016, which was developed by Tsinghua University (Zheng et al., 2018). To reduce the uncertainty attributed to the outdated spatial surrogates in the spatialtemporal emission allocation process, we utilized the population distribution data from the LandScan 2017 database 

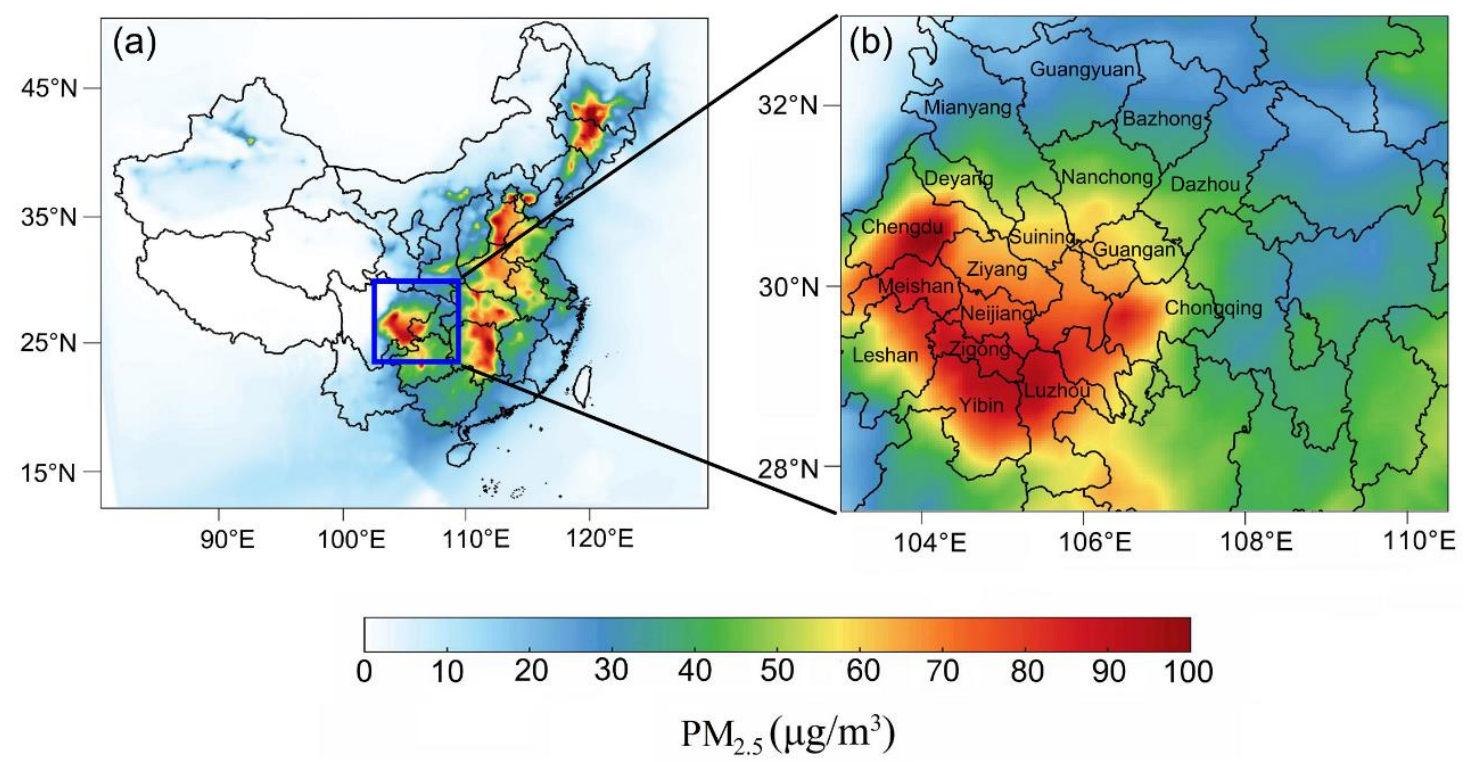

Fig. 1. Average simulated surface $\mathrm{PM}_{2.5}$ concentrations in domain I of China (a) and the Sichuan Basin (SCB) (b) in January 2017.

and GDP data from the database of the National Bureau of Statistics of China (NBSC) to allocate the emissions to the grid cells (Deng et al., 2020). The Model of Emissions of Gases and Aerosols from Nature (MEGAN, version 2.1) was used to calculate the biogenic emissions (Guenther et al., 2012). The options for the physical and chemical parameterizations of the WRF-CMAQ model are listed in Table 1.

\section{Numerical Experiments}

Four sensitivity experiments were performed to quantify the contributions of local emissions and regional transport during the studied episode, as shown in Table 2. In the BASE simulation, all anthropogenic and biogenic emissions were included. In the No-Anth experiment, only biogenic emissions were included. In the NoCD-Anth experiment, the anthropogenic emissions in Chengdu city were turned off. In contrast, we considered only anthropogenic emissions in Chengdu city in the OnlyCD-Anth experiment. Based on the above experiments, the relative contribution from regional transport was determined by comparing the simulation results of BASE to those of OnlyCD-Anth. The contribution from local emissions to the $\mathrm{PM}_{2.5}$ concentration was identified by subtracting the NoCD-Anth results from the BASE results.

\section{Process Analysis}

Process analysis (PA) is a diagnostic method incorporated into the CMAQ model and includes integrated process rate (IPR) analysis and integrated reaction rate (IRR) analysis (Byun and Ching, 1999). The IPR method has been widely used to track the hourly relative contributions of physical/chemical processes to $\mathrm{PM}_{2.5}$ concentrations in previous studies (Gao et al., 2014; Fan et al., 2015; Huang et al., 2016). In this study, the IPR method was used to assess the processes that influence simulated $\mathrm{PM}_{2.5}$ concentrations. The nine types of processes are gas-phase chemistry (denoted CHEM), emission sources (denoted EMIS), aerosol processes (denoted AERO), cloud processes (denoted CLDS), dry deposition (denoted DDEP), horizontal advection (denoted HADV), horizontal diffusion (denoted HDIF), vertical advection (denoted ZADV) and vertical diffusion (denoted VDIF). It should be noted that horizontal transport (denoted HTRA) is defined as the sum of horizontal advection and horizontal diffusion, and vertical transport (denoted VTRA) is defined as the sum of vertical advection and vertical diffusion.

\section{MODEL EVALUATION}

\section{Meteorological Parameters}

We evaluated the performance of the WRF model to demonstrate the capability of the modeling system through verification statistics, including the normalized mean bias (NMB), the index of agreement (IOA), and the root mean square error (RMSE), for the hourly 2-m temperature (T2), $2-\mathrm{m}$ relative humidity (RH2), 10-m wind speed (WS10) and 10-m wind direction (WD10) at the Chengdu, Meishan, Ziyang and Neijiang meteorological stations. As shown in Table 3 , the simulated $\mathrm{T} 2$ and $\mathrm{RH} 2$ agreed well with the observations, with IOA values higher than 0.80 , indicating that the model successfully captured the variation in T2 and RH2 in these four cities. For WS10 and WD10, the model displayed negative bias, with NMB values ranging from 16.69-42.36 and from 28.79-36.29, respectively. This bias may be attributed to the complex basin terrain and planetary boundary layer parameterization. Overall, these comparisons clearly demonstrate that the WRF model adequately reproduced the meteorological conditions.

\section{PM2.5 and its Chemical Components}

Fig. 2 shows the time series of simulated hourly $\mathrm{PM}_{2.5}$ concentrations in the BASE simulation and the observed $\mathrm{PM}_{2.5}$ levels in the four cities from 20 to 30 January 2017. 
Table 1. Modeling configuration used for the WRF-CMAQ simulations.

\begin{tabular}{ll}
\hline Model attribution & Configuration \\
\hline Simulation period & 15 January 2016 to 31 January 2017 (5-day spin-up period) \\
Domain & Sichuan Basin; Center $=30^{\circ} \mathrm{N}, 104^{\circ} \mathrm{E}$ \\
Horizontal resolution & $27 \mathrm{~km} / 9 \mathrm{~km} / 3 \mathrm{~km}$ \\
Vertical resolution & 30 layers from the surface to $50 \mathrm{hPa}$ \\
Microphysics & Lin scheme \\
PBL physics scheme & Yonsei University (YSU) scheme \\
Shortwave and longwave radiation & Rapid Radiative Transfer Model for GCMs (RRTMG) \\
Land surface model & Noah land surface model \\
Gas-phase chemistry & Carbon bond chemical reaction mechanism $(\mathrm{CB} 06)$ \\
Aerosol module/size & AERO6/3 modes \\
\hline
\end{tabular}

Table 2. Statistical metrics for comparing the observations and simulations.

\begin{tabular}{ll}
\hline Simulation & Description \\
\hline BASE & All anthropogenic and biogenic emissions are included \\
No-Anth & Only biogenic emissions are included \\
NoCD-Anth & Anthropogenic emissions in Chengdu city are excluded \\
OnlyCD-Anth & Considers only anthropogenic emissions in Chengdu city \\
\hline
\end{tabular}

Table 3. Statistical metrics between the observations and simulations.

\begin{tabular}{llllll}
\hline & & Chengdu & Meishan & Zigong & Neijiang \\
\hline 2-m Temperature & NMB & -6.62 & -3.69 & -9.68 & -11.36 \\
& RMSE & 4.16 & 2.12 & 6.47 & 6.81 \\
& IOA & 0.94 & 0.97 & 0.91 & 0.91 \\
\multirow{3}{*}{-m Relative Humidity } & NMB & -6.69 & -10.49 & -11.2 & -13.2 \\
& RMSE & 15.81 & 14.64 & 12.28 & 16.49 \\
\multirow{2}{*}{$10-\mathrm{m}$ Wind Speed } & IOA & 0.86 & 0.80 & 0.89 & 0.79 \\
& NMB & 16.69 & 22.85 & 37.41 & 42.36 \\
\multirow{2}{*}{$10-\mathrm{m}$ Wind Direction } & RMSE & 2.03 & 2.19 & 3.32 & 2.94 \\
& IOA & 0.72 & 0.62 & 0.66 & 0.69 \\
& NMB & 28.79 & 36.29 & 35.78 & 29.46 \\
& RMSE & 46.97 & 56.81 & 42.23 & 49.44 \\
\hline
\end{tabular}

Generally, the CMAQ model reasonably reproduced the temporal evolution of the observed $\mathrm{PM}_{2.5}$ concentrations in the four cities, with IOAs of $0.89,0.84,0.80$, and 0.93 and mean biases of $-12.3 \mu \mathrm{g} \mathrm{m}^{-3},-16.8 \mu \mathrm{g} \mathrm{m}^{-3},-23.6 \mu \mathrm{g} \mathrm{m}^{-3}$ and $-5.8 \mu \mathrm{g} \mathrm{m}^{-3}$ for Chengdu, Meishan, Ziyang and Neijiang, respectively. In general, the CMAQ model captured the peaks and temporal variations in the $\mathrm{PM}_{2.5}$ concentrations from 20 to 28 January in these cities but underestimated the peak $\mathrm{PM}_{2.5}$ concentration on 28 January in Zigong.

Fig. 3 compares the simulated and observed OM, $\mathrm{SO}_{4}{ }^{2-}$, $\mathrm{NO}_{3}^{-}$, and $\mathrm{NH}_{4}{ }^{+}$concentrations at the CDAES site averaged from 20 to 30 January 2017. The CMAQ model underestimated the concentrations of $\mathrm{OM}, \mathrm{SO}_{4}{ }^{2-}$ and $\mathrm{NO}_{3}{ }^{-}$by $0.8 \mu \mathrm{g} \mathrm{m}^{-3}$, $2.3 \mu \mathrm{g} \mathrm{m}^{-3}$, and $5.1 \mu \mathrm{g} \mathrm{m}^{-3}$, respectively, but overestimated the $\mathrm{NH}_{4}{ }^{+}$concentration by $1.3 \mu \mathrm{g} \mathrm{m} \mathrm{m}^{-3}$. For OM, the underestimation may have been attributed to the lack of SOA parameterizations in the AERO06 aerosol module. The bias associated with SIAs (including $\mathrm{NH}_{4}{ }^{+}, \mathrm{SO}_{4}{ }^{2-}$ and $\mathrm{NO}_{3}{ }^{-}$) has also been noted in previous studies and potentially derives from the lack of heterogeneous reactions in the chemistry mechanisms in the models, the allocation bias for emission inventories, and the failure to capture relevant changes in meteorological conditions (Zheng et al., 2015).

\section{RESULTS AND DISCUSSION}

\section{Spatiotemporal Evolution of Severe Haze Formation}

The weather conditions and air pollutant concentrations in four highly polluted cities during this episode are presented in Fig. 4. During this severe haze episode, the $\mathrm{PM}_{2.5}$ concentrations in these cities all reached peak values on January 28th; notably, the surface $\mathrm{PM}_{2.5}$ concentration rapidly increased from $100 \mu \mathrm{g} \mathrm{m}^{-3}$ to more than $600 \mu \mathrm{g} \mathrm{m}^{-3}$ in less than a day in Neijiang and Zigong; these peaks were the highest values recorded in 2017. The weather conditions in the SCB were characterized by persistent high relative humidity greater than $90 \%$ and low WS10 (less than $3 \mathrm{~m} \mathrm{~s}^{-1}$ ) during this period.

Fig. 5 shows the spatial distributions of the simulated daily mean surface $\mathrm{PM}_{2.5}$ concentrations within the SCB from 20 to 28 January 2017. Before the haze episode (e.g., on January 20), the daily $\mathrm{PM}_{2.5}$ concentration in most areas 

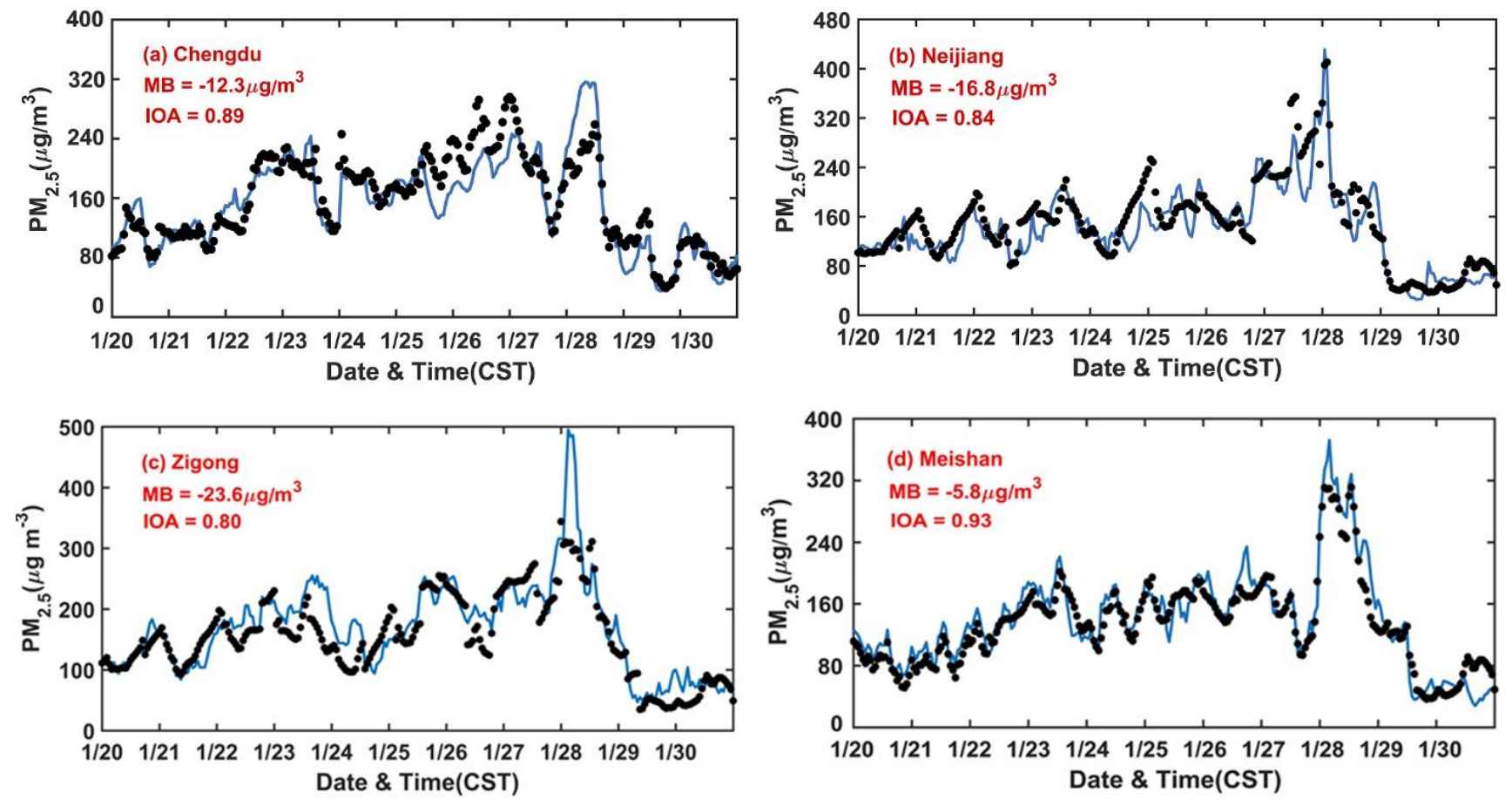

Fig. 2. Comparison of the observed (blue line) and simulated (black dots) hourly surface $\mathrm{PM}_{2.5}$ concentrations in four cities in the Sichuan Basin (SCB) from 20 January to 30 January 2017.

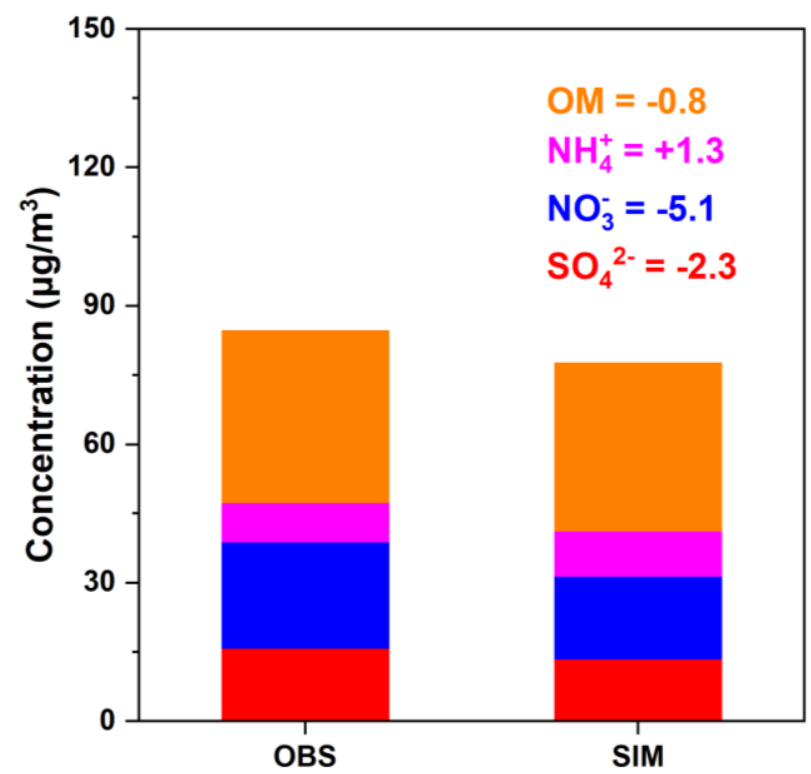

Fig. 3. Comparison of the observed and simulated surface mass concentrations $\left(\mu \mathrm{g} \mathrm{m}^{-3}\right)$ of $\mathrm{SO}_{4}{ }^{2-}$ (red), $\mathrm{NO}_{3}{ }^{-}$(blue), $\mathrm{NH}_{4}{ }^{+}$(purple), OM (orange) at CDAES site $\left(30^{\circ} 56^{\prime} \mathrm{N}\right.$, $104^{\circ} 05^{\prime} \mathrm{E}$ ) averaged over 20-30 January 2017. Mean biases (MB, unit: $\mu \mathrm{g} \mathrm{m}^{-3}$ ) are also listed for each species (colored numbers).

of the SCB was less than $100 \mu \mathrm{g} \mathrm{m}^{-3}$ under a prevailing clean southerly air flow. On 21 January, a uniform pressure field was present over the basin, and the regional average WS was less than $3 \mathrm{~m} \mathrm{~s}^{-1}$. The boundary layer became stable (see Fig. S3), which was favorable for constraining the aerosol particles within the low mixing layer. Consequently, a high $\mathrm{PM}_{2.5}$ belt formed over the western SCB, with the daily mean $\mathrm{PM}_{2.5}$ concentration exceeding $140 \mu \mathrm{g} \mathrm{m}^{-3}$. During this stage, a uniform pressure field continuously controlled most regions of the $\mathrm{SCB}$, resulting in $\mathrm{PM}_{2.5}$ concentrations higher than $120 \mu \mathrm{g} \mathrm{m}^{-3}$. However, on 26 January, the SCB was affected by effective convection caused by synoptic conditions, resulting in a temporary decrease in the concentration of $\mathrm{PM}_{2.5}$ due to wet scavenging by precipitation. On 27 January, the weather pattern over the SCB was characterized by strong anticyclonic circulation. Moreover, the SCB is located behind a ridge centered in eastern Tibetan (Fig. S4(g)), which causes the prevailing regional wind field to transition to strong southeasterly winds. Therefore, air masses were transported from south to north, leading to a significant increase in the $\mathrm{PM}_{2.5}$ concentration in Chengdu and the surrounding areas, with the maximum daily mean value exceeding $270 \mu \mathrm{g} \mathrm{m}^{-3}$. After 28 January, the SCB was affected by northerly winds that brought dry and clean air masses into the basin. The $\mathrm{PM}_{2.5}$ concentrations in most areas of the SCB decreased to 40-100 $\mathrm{\mu g} \mathrm{m}^{-3}$.

Based on the evolution pattern of simulated $\mathrm{PM}_{2.5}$ concentrations over the SCB, we divide this episode into four stages:

(I) The aerosol accumulation stage (20-25 January). In Stage I, the daily mean $\mathrm{PM}_{2.5}$ concentrations averaged over the SCB slowly increased from 30.8 to $240.7 \mu \mathrm{g} \mathrm{m}^{-3}$, and these levels persisted for five days.

(II) The clearance stage (26 January). The $\mathrm{PM}_{2.5}$ concentrations in the SCB decreased to $80 \mu \mathrm{g} \mathrm{m}^{-3}$, which was caused by precipitation.

(III) The rapid formation stage (27-28 January). During this 

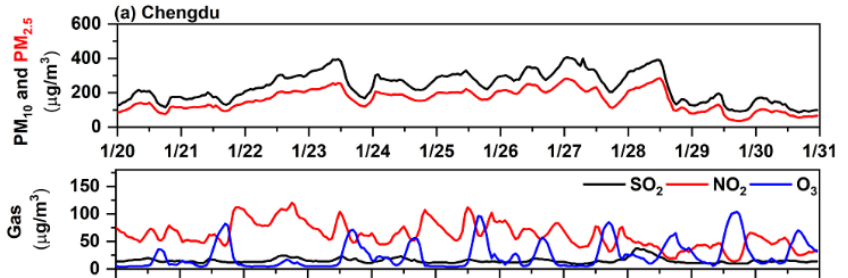

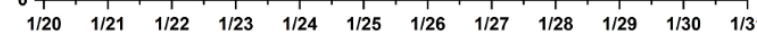

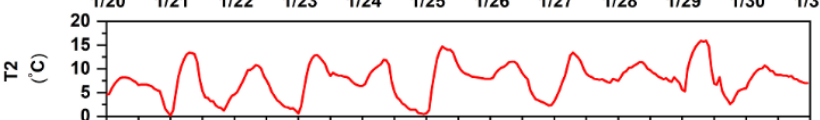

$\begin{array}{llllllllllll}1 / 20 & 1 / 21 & 1 / 22 & 1 / 23 & 1 / 24 & 1 / 25 & 1 / 26 & 1 / 27 & 1 / 28 & 1 / 29 & 1 / 30 & 1 / 3\end{array}$

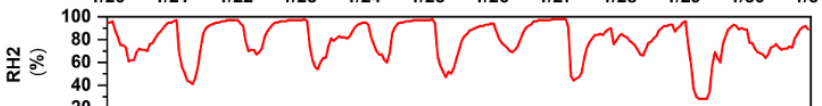

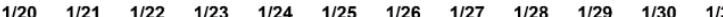
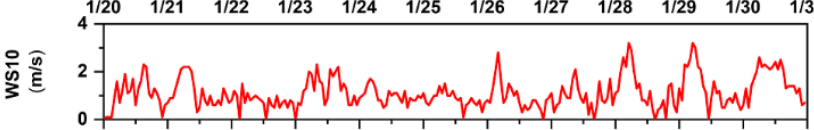

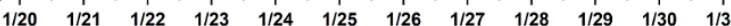

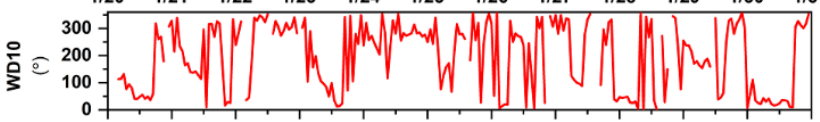

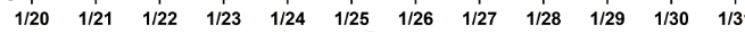

N 800 (c) Neijiang
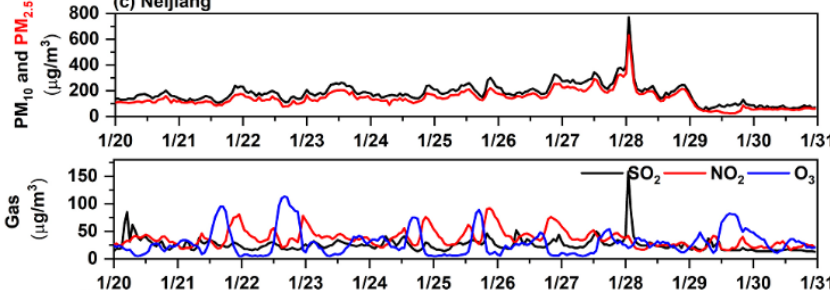

$\begin{array}{llllllllllll}1 / 20 & 1 / 21 & 1 / 22 & 1 / 23 & 1 / 24 & 1 / 25 & 1 / 26 & 1 / 27 & 1 / 28 & 1 / 29 & 1 / 30 & 1 / 31\end{array}$

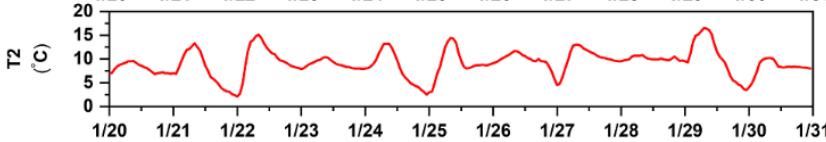

帘气
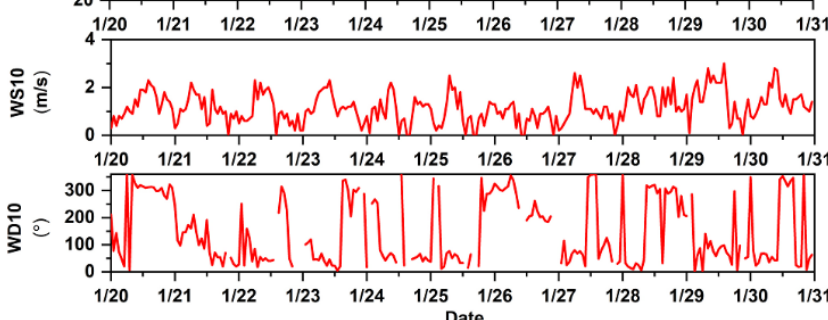
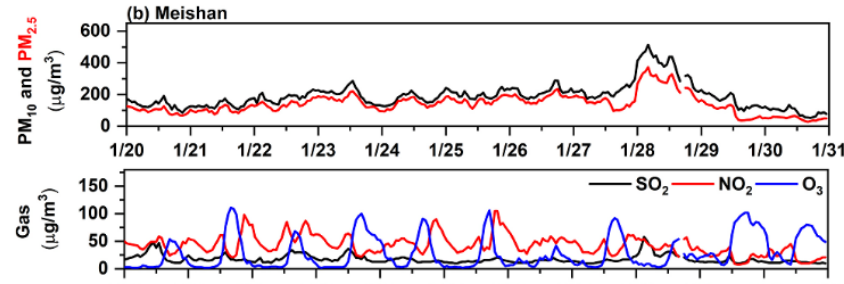

$\begin{array}{llllllllllll}1 / 20 & 1 / 21 & 1 / 22 & 1 / 23 & 1 / 24 & 1 / 25 & 1 / 26 & 1 / 27 & 1 / 28 & 1 / 29 & 1 / 30 & 1 / 31\end{array}$
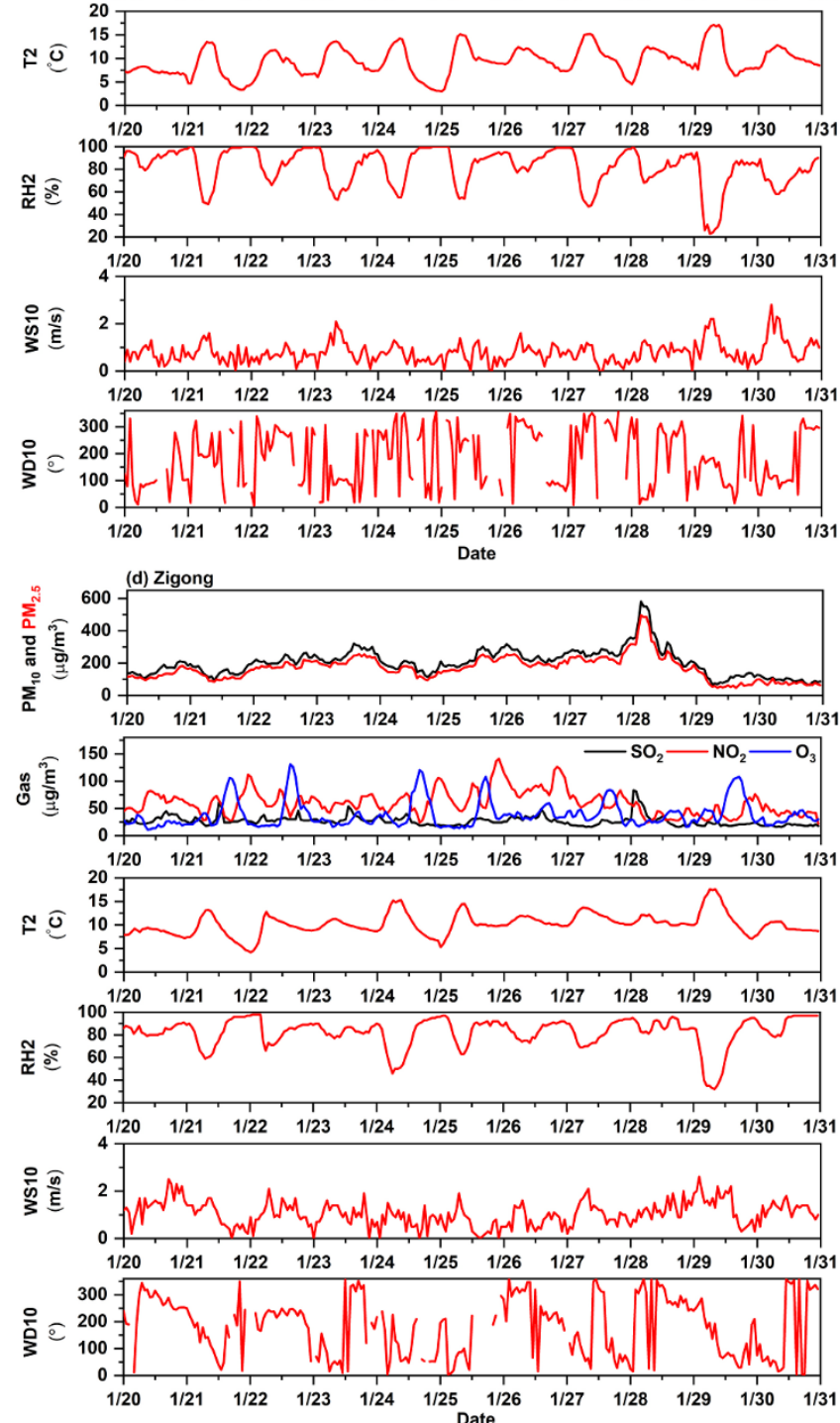

Fig. 4. Evolution of the observed $\mathrm{PM}_{2.5}, \mathrm{PM}_{10}$, and gaseous pollutant concentrations; 2-m temperature (T2); 2-m relative humidity (RH2); 10-m wind speed (WS10); and 10-m wind direction (WD10) in January 2017 in four cities: (a) Chengdu, (b) Meishan, (c) Neijiang, and (d) Zigong.

stage, the daily average $\mathrm{PM}_{2.5}$ concentrations in most cities of the SCB reached the "heavily polluted" air quality threshold value (24-h average $\mathrm{PM}_{2.5}$ concentration $>150 \mu \mathrm{g} \mathrm{m}^{-3}$ ). In Neijiang and Leshan, the $\mathrm{PM}_{2.5}$ concentration even reached 897 and $724 \mu \mathrm{g} \mathrm{m}^{-3}$, respectively.

(IV) The aerosol dispersion stage (29-31 January). In this stage, the $\mathrm{PM}_{2.5}$ concentration gradually decreased dramatically to low levels (50-72 $\left.\mu \mathrm{g} \mathrm{m}^{-3}\right)$ with increasing WS10.

\section{Contributions from Local Emissions versus Regional Transport}

Previous studies have indicated that local anthropogenic emissions are the major source of high $\mathrm{PM}_{2.5}$ concentrations during severe haze episodes in the SCB (Fan et al., 2020). Despite the dominant contribution from local emissions, the contribution of regional transport to $\mathrm{PM}_{2.5}$ concentrations has not been fully quantified in the SCB (Zhao et al., 2019). Regional transport is responsible for more than $30 \%$ of the $\mathrm{PM}_{2.5}$ concentration variations in the SCB during winter 

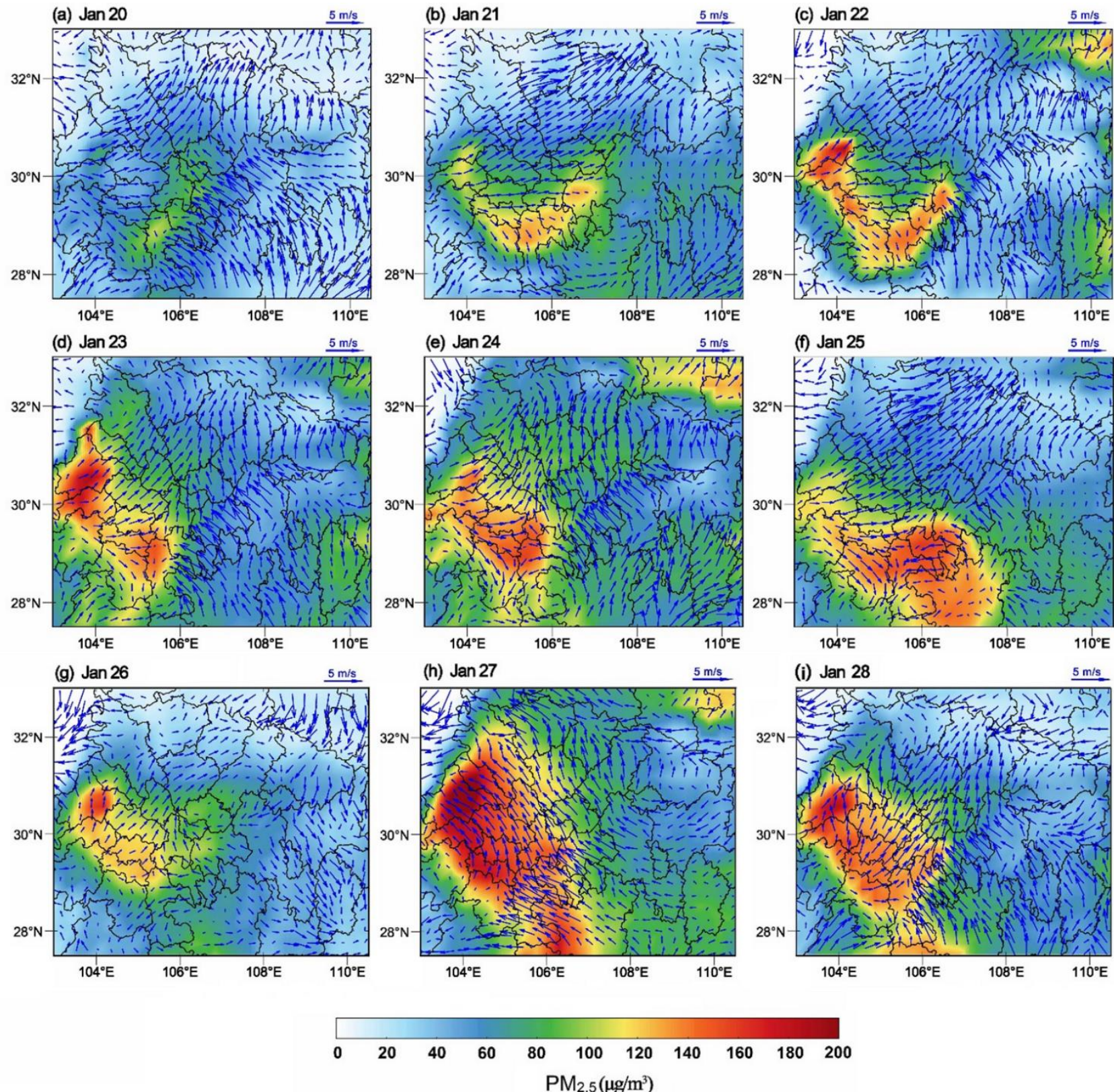

Fig. 5. The spatial distributions of simulated daily $\mathrm{PM}_{2.5}$ concentrations (shaded, $\mu \mathrm{g} \mathrm{m}^{-3}$ ) and wind vectors (arrows, $\mathrm{m} \mathrm{s}^{-1}$ ) from 20 to 28 January 2017

(Qiao et al., 2019b). In this section, we discuss the contributions of local anthropogenic emissions and regional transport to the $\mathrm{PM}_{2.5}$ concentration in the SCB to determine the relative importance of each factor during the studied severe haze episode.

Fig. 6 illustrates the relative contributions of local emissions and regional transport to the simulated $\mathrm{PM}_{2.5}$ level in Chengdu city. The episode featured different evolution processes, with a gradual $\mathrm{PM}_{2.5}$ increase in Stage I and an explosive $\mathrm{PM}_{2.5}$ increase in Stage III. In Stage I, the stagnant conditions near the surface and low WS10 were not conducive to the dispersion of air pollutants, which led to the local accumulation and chemical production of secondary pollutants. Therefore, the relatively high $\mathrm{PM}_{2.5}$ concentration
(141.1 $\mu \mathrm{g} \mathrm{m}^{-3}$ ) was principally caused by local emissions during Stage I. In Stage II, the $\mathrm{PM}_{2.5}$ concentration in Chengdu was mainly associated with the combined effects of local emissions and regional transport. The contributions of local emissions and regional transport to the $\mathrm{PM}_{2.5}$ concentration were comparable in this stage (44\% versus $52 \%$, respectively). The cross-border transport of polluted air masses from the southern SCB under prevailing southeasterly winds was the main contributor to haze formation in Stage III, with the contribution of regional transport reaching $66 \%$ and that of local emissions reaching 32\%. During Stage IV, the $\mathrm{PM}_{2.5}$ levels in Chengdu were dominated by local contributions $(58 \%)$, and the contribution from regional transport decreased to $38 \%$. 


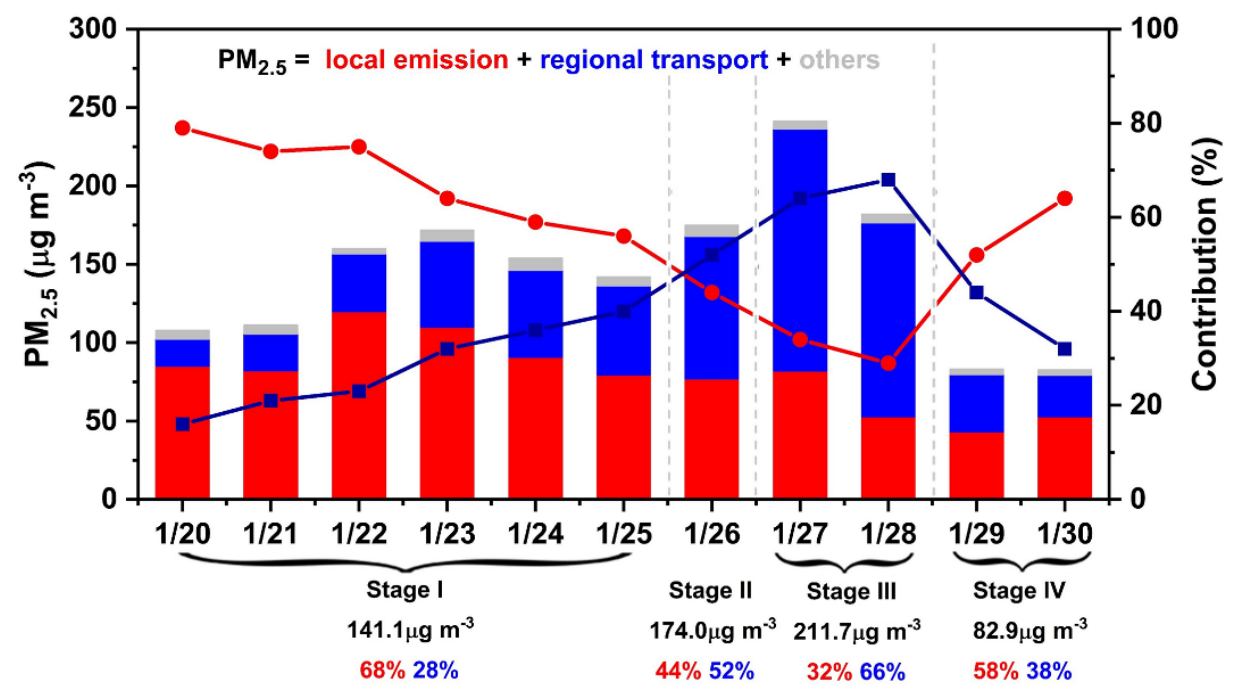

Fig. 6. Contributions of local emissions (red) and regional transport (blue) to the surface $\mathrm{PM}_{2.5}$ concentrations averaged over Chengdu from 20 to 30 January 2017. The absolute contributions $\left(\mu \mathrm{g} \mathrm{m}^{-3}\right)$ are shown using bars, and the percent contributions $(\%)$ are shown using lines. The $\mathrm{PM}_{2.5}$ concentration and the percent contributions averaged over each stage are listed at the bottom of the figure. Note: The "others" contribution represents the $\mathrm{PM}_{2.5}$ concentration biased from the brute force method.

However, it should be noted that the brute force method used in this study to attribute the contribution of local emissions and regional transport has limitations due to nonlinearities of the chemistry of $\mathrm{PM}_{2.5}$ formation (Clappier et al., 2017; Thunis et al., 2019). Although the brute force method has been widely used in estimating the contributions of $\mathrm{PM}_{2.5}$ sources (Kim et al., 2017; Chen et al., 2019; Cheng et al., 2019), further investigations using source-oriented methods such as CAMx-PSAT and CMAQ-ISAM should be considered to reduce the nonlinear effects in future studies.

\section{Process Analysis of Variations in the PM2.5 Concentration}

Fig. 7 shows the hourly contributions of individual atmospheric physical and chemical processes to variations in the surface $\mathrm{PM}_{2.5}$ concentration over Chengdu in different stages. In the beginning of Stage I, EMIS was the dominant source of surface $\mathrm{PM}_{2.5}$ in Chengdu and was responsible for $72.8 \%$ of the accumulated $\mathrm{PM}_{2.5}$. Compared with the dominant effect of EMIS on the $\mathrm{PM}_{2.5}$ concentration, the contribution of AERO to surface $\mathrm{PM}_{2.5}$ was relatively small, accounting for only $\sim 8.8 \%$ of the accumulated $\mathrm{PM}_{2.5}$ mass concentration. The contribution of CLDS was almost negligible in the surface layer. DDEP, HTRA and VTRA were the major removal pathways of $\mathrm{PM}_{2.5}$, accounting for $\sim 6.6, \sim 14.8 \%$ and $\sim 76.4 \%$ of the removal, respectively. The maximum positive contribution of EMIS was observed during rushhour periods (07:00-08:00 and 16:00-19:00), whereas the maximum negative contributions of VTRA appeared at midnight. The PA results in the middle of Stage I (January 21-22) differed from those at the beginning of Stage I. Even though EMIS still acted as the predominate contributor to $\mathrm{PM}_{2.5}$, HTRA gradually became the second largest source of surface $\mathrm{PM}_{2.5}$, accounting for $24.3 \%$. In Stage II, the contribution of AERO to the surface $\mathrm{PM}_{2.5}$ was quite low compared with that in Stage I. Notably, the $\mathrm{PM}_{25}$ concentration decreased dramatically during this stage, which can be attributed to wet deposition as a result of precipitation events (as discussed before). When the episode reached Stage III, the contribution from HTRA increased dramatically, as an important source of $\mathrm{PM}_{2.5}$ in addition to primary emissions. This phenomenon reflected the important role of regional $\mathrm{PM}_{2.5}$ transport from the southern SCB to Chengdu and the surrounding areas under the prevailing wind fields (see Fig. 5(h)-5(i)). Additionally, VTRA still had a negative influence on the $\mathrm{PM}_{2.5}$ concentration and was responsible for $\sim 88 \%$ of the reduction. It should be noted that the maximum negative contributions of VTRA in Stage III appeared at night due to the strong southeasterly winds. During Stage IV, although EMIS still acted as a stable source of $\mathrm{PM}_{2.5}$, HTRA became the main process of $\mathrm{PM}_{2.5}$ removal, leading to a gradual decrease in the $\mathrm{PM}_{2.5}$ concentration. In summary, the rapid increase in $\mathrm{PM}_{2.5}$ in Chengdu was mainly attributed to HTRA, which reflected the influence of regional transport from the southern and southeastern SCB. Furthermore, the essential role of primary EMIS, which acted as a stable positive contributor to $\mathrm{PM}_{2.5}$, cannot be neglected.

\section{CONCLUSIONS}

In this study, we comprehensively investigate the formation and evolution mechanisms of a severe regional haze episode that occurred over the SCB from 20 January 2017 to 31 January 2017. The roles of local emissions and regional transport in the haze episode were identified by sensitivity experiments. Additionally, the IPR method was used to quantify the contributions of each physical/chemical process to the variation in the $\mathrm{PM}_{2.5}$ concentration.

Four haze stages were identified, with a record-breaking hazy episode with a peak concentration of nearly $400 \mu \mathrm{g} \mathrm{m}^{-3}$ 


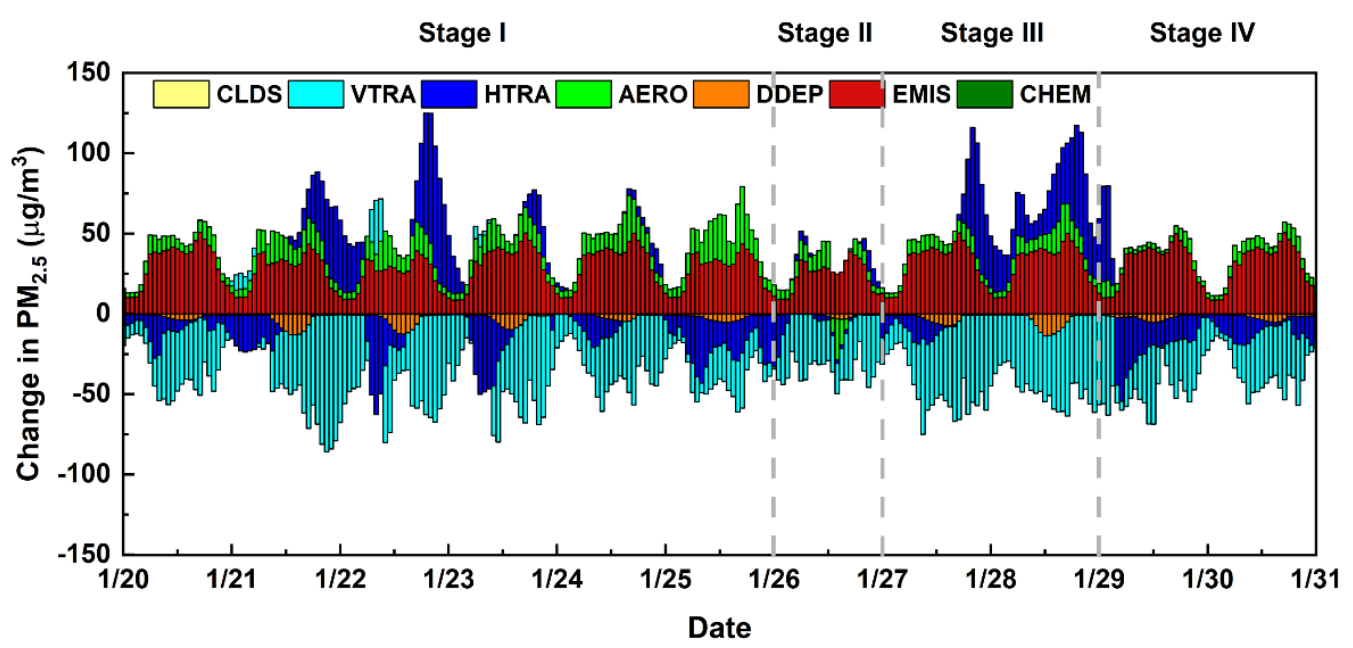

Fig. 7. Hourly contributions of individual processes to the $\mathrm{PM}_{2.5}$ mass concentration in Chengdu from 20 January 2017 to 31 January 2017.

was observed on 27 January. Sensitivity experiments indicated that the local emissions in Chengdu accounted for $46 \%$ of the total $\mathrm{PM}_{2.5}$ concentrations on average, thus acting as a stable positive contributor. In Stage I, the concentration of surface $\mathrm{PM}_{2.5}$ was controlled by local emissions (68\%). The contribution of regional transport from the areas within the simulation domain, excluding Chengdu, increased significantly (Stages II and III), which was the main cause of the persistent severe episode. Therefore, joint emission control is the most effective way to mitigate regional haze pollution.

Based on the IPR analysis, emissions (EMIS) and aerosol chemistry (AERO) were the major sources of pollutants and were responsible for $1.3 \%$ and $5.2 \%$ of the $\mathrm{PM}_{2.5}$, respectively. In contrast, the main sinks were VTRA and DDEP during the study period, accounting for $9.4 \%$ and $5.2 \%$ of reduction, respectively. However, the substantial $\mathrm{PM}_{2.5}$ increase in Chengdu during the rapid formation stage was attributed to the positive contribution of HTRA, indicating that regional transport is significant in regional haze formation. This work and previous studies all highlighted the essential role of cross-border transport between cities inside SCB in wintertime haze episodes. To further promote our understanding on severe haze episodes occurred over SCB in wintertime, future work should be considered on elucidating the formation of organic aerosols under high $\mathrm{RH}$ and cloudy conditions. Additional work is also needed to identify the contribution from different source regions to the $\mathrm{PM}_{2.5}$ and major transport pathways at different heights in order to further understand the regional transport mechanism (Huang et al., 2020).

\section{ACKNOWLEDGMENTS}

This study was funded by the National Natural Science Foundation of China (No. 41705080, No. 41975131, No.91744209), the National Key Foundation Study Developing Programs (No. 2019YFC0214601) and the Scientific Research Foundation of the Chengdu University of Information Technology (No. KYTZ201823). The authors would like to acknowledge the MEIC team from Tsinghua
University for providing the Multiscale Emission Inventory of China (MEIC) data. We also greatly acknowledge the Chengdu Environmental Science Research Institute for providing the data on the chemical components of $\mathrm{PM}_{2.5}$. The datasets generated during and/or analyzed in this study are available upon request to the corresponding author.

\section{SUPPLEMENTARY MATERIAL}

Supplementary data associated with this article can be found in the online version at https://doi.org/10.4209/aaqr.2 020.04.0173

\section{REFERENCES}

Chan, C. K. and Yao, X. (2008). Air pollution in mega cities in China. Atmos. Environ. 42: 1-42. https://doi.org/10.10 16/j.atmosenv.2007.09.003

Chen, L., Zhu, J., Liao, H., Gao, Y., Qiu, Y., Zhang, M., Liu, Z., Li, N. and Wang, Y. (2019). Assessing the formation and evolution mechanisms of severe haze pollution in the Beijing-Tianjin-Hebei region using process analysis. Atmos. Chem. Phys. 19: 10845-10864. https://doi.org/10. 5194/acp-19-10845-2019

Chen, Y., Xie, S., Luo, B. anf Zhai, C. (2014). Characteristics and origins of carbonaceous aerosol in the Sichuan Basin, China. Atmos. Environ. 94: 215-223. https://doi.org/10.1 016/j.atmosenv.2014.05.037

Cheng, J., Su, J., Cui, T., Li, X., Dong, X., Sun, F., Yang, Y., Tong, D., Zheng, Y., Li, Y., Li, J., Zhang, Q. and He, K. (2019). Dominant role of emission reduction in $\mathrm{PM}_{2.5}$ air quality improvement in Beijing during 2013-2017: A model-based decomposition analysis. Atmos. Chem. Phys. 19: 6125-6146. https://doi.org/10.5194/acp-19-6125-2019

Clappier, A., Belis, C.A., Pernigotti, D. and Thunis, P. (2017). Source apportionment and sensitivity analysis: Two methodologies with two different purposes. Geosci. Model Dev. 10: 4245-4256. https://doi.org/10.5194/gmd$10-4245-2017$ 
Deng, F., Lv, Z., Qi, L., Wang, X., Shi, M. and Liu, H. (2020). A big data approach to improving the vehicle emission inventory in China. Nat. Commun. 11: 2801. https://doi.org/10.1038/s41467-020-16579-w

Emmons, L.K., Walters, S., Hess, P.G., Lamarque, J.F., Pfister, G.G., Fillmore, D. Granier, C., Guenther, A., Kinnison, D., Laepple, T., Orlando, J., Tie, X., Tyndall, G., Wiedinmyer, C., Baughcum, S.L. and Kloster, S. (2010). Description and evaluation of the Model for Ozone and Related chemical Tracers, version 4 (MOZART-4). Geosci. Model Dev. 3: 43-67. https://doi.org/10.5194/gmd3-43-2010

Fan, J., Shang, Y., Zhang, X., Wu, X., Zhang, M., Cao, J., Luo, B., Zhang, X., Wang, S., Li, S., Liu, H. and Wu, P. (2020). Joint pollution and source apportionment of $\mathrm{PM}_{2.5}$ among three different urban environments in Sichuan Basin, China. Sci. Total Environ. 714: 136305. https://doi.org/10.1016/j.scitotenv.2019.136305

Fan, Q., Lan, J., Liu, Y., Wang, X., Chan, P., Hong, Y., Feng, Y., Liu, Y., Zeng, Y. and Liang, G. (2015). Process analysis of regional aerosol pollution during spring in the Pearl River Delta region, China. Atmos. Environ. 122: 829 838. https://doi.org/10.1016/j.atmosenv.2015.09.013

Gao, L., Zhang, R., Han, Z., Fu, C., Yan, P., Wang, T., Hong, S. and Jiao, L. (2014). A modeling study of a typical winter $\mathrm{PM}_{2.5}$ pollution episode in a city in Eastern China. Aerosol Air Qual. Res. 14: 311-322. https://doi.org/10.42 09/aaqr.2013.02.0054

Guenther, A.B., Jiang, X., Heald, C.L., Sakulyanontvittaya, T., Duhl, T., Emmons, L.K. and Wang, X. (2012). The Model of Emissions of Gases and Aerosols from Nature version 2.1 (MEGAN2.1): An extended and updated framework for modeling biogenic emissions. Geosci. Model Dev. 5: 1471-1492. https://doi.org/10.5194/gmd5-1471-2012

Huang, X., Ding, A., Wang, Z., Ding, K., Gao, J., Chai, F. and $\mathrm{Fu}, \mathrm{C}$. (2020). Amplified transboundary transport of haze by aerosol-boundary layer interaction in China. Nat. Geosci. 13: 428-434. https://doi.org/10.1038/s41561-0200583-4

Huang, Z., Ou, J., Zheng, J., Yuan, Z., Yin, S., Chen, D. and Tan, H. (2016). Process contributions to secondary inorganic aerosols during typical pollution episodes over the Pearl River Delta Region, China. Aerosol Air Qual. Res. 16: 2129-2144. https://doi.org/10.4209/aaqr.2015.1 2.0668

Kim, H. C., Kim, E., Bae, C., Cho, J.H., Kim, B.U. and Kim, S. (2017). Regional contributions to particulate matter concentration in the Seoul metropolitan area, South Korea: Seasonal variation and sensitivity to meteorology and emissions inventory. Atmos. Chem. Phys. 17: 1031510332. https://doi.org/10.5194/acp-17-10315-2017

Kong, L., Tan, Q., Feng, M., Qu, Y., An, J., Liu, X., Cheng, N., Deng, Y., Zhai, R. and Wang, Z. (2020). Investigating the characteristics and source analyses of $\mathrm{PM}_{2.5}$ seasonal variations in Chengdu, Southwest China. Chemosphere 243: 125267. https://doi.org/10.1016/j.chemosphere.201 9.125267

Lei, Y., Zhang, Q., He, K.B. and Streets, D.G. (2011). Primary anthropogenic aerosol emission trends for China, 19902005. Atmos. Chem. Phys. 11: 931-954. https://doi.org/10. 5194/acp-11-931-2011

Li, J., Du, H., Wang, Z., Sun, Y., Yang, W., Li, J., Tang, X. and Fu, P. (2017). Rapid formation of a severe regional winter haze episode over a mega-city cluster on the North China Plain. Environ. Pollut. 223: 605-615. https://doi.org/10.1016/j.envpol.2017.01.063

Luo, J., Zhang, J., Huang, X., Liu, Q., Luo, B., Zhang, W., Rao, Z. and Yu, Y. (2020). Characteristics, evolution, and regional differences of biomass burning particles in the Sichuan Basin, China. J. Environ. Sci. 89: 35-46. https://doi.org/10.1016/j.jes.2019.09.015

Qiao, X., Guo, H., Wang, P., Tang, Y., Ying, Q., Zhao, X., Deng, W. and Zhang, H. (2019a). Fine particulate matter and ozone pollution in the 18 cities of the sichuan basin in southwestern China: Model performance and characteristics. Aerosol Air Qual. Res. 19: 2308-2319. https://doi.org/10.4209/aaqr.2019.05.0235

Qiao, X., Guo, H., Tang, Y., Wang, P., Deng, W., Zhao, X., Hu, J., Ying, Q. and Zhang, H. (2019b). Local and regional contributions to fine particulate matter in the 18 cities of Sichuan Basin, southwestern China. Atmos. Chem. Phys. 19: 5791-5803. https://doi.org/10.5194/acp19-5791-2019

Song, M., Tan, Q., Feng, M., Qu, Y., Liu, X., An, J. and Zhang, Y. (2018). Source apportionment and secondary transformation of atmospheric nonmethane hydrocarbons in Chengdu, Southwest China. J. Geophys. Res. 123: 9741-9763. https://doi.org/10.1029/2018JD028479

Song, M., Liu, X., Tan, Q., Feng, M., Qu, Y., An, J. and Zhang, Y. (2019). Characteristics and formation mechanism of persistent extreme haze pollution events in Chengdu, southwestern China. Environ. Pollut. 251: 112. https://doi.org/10.1016/j.envpol.2019.04.081

Sun, Y., Zhuang, G., Tang, A., Wang, Y. and An, Z. (2006). Chemical characteristics of $\mathrm{PM}_{2.5}$ and $\mathrm{PM}_{10}$ in haze-fog episodes in Beijing. Environ. Sci. Technol. 40: 31483155. https://doi.org/10.1021/es051533g

Sun, Y., Niu, T., He, J., Ma, Z., Liu, P., Xiao, D., Hu, J., Yang, J. and Yan, X. (2020). Classification of circulation patterns during the formation and dissipation of continuous pollution weather over the Sichuan Basin, China. Atmos. Environ. 223: 117244. https://doi.org/10.1016/j.atmosenv. 2019.117244

Tao, J., Zhang, Z., Tan, H., Zhang, L., Wu, Y., Sun, J., Che, H., Cao, J., Cheng, P., Chen, L. and Zhang, R. (2018). Observational evidence of cloud processes contributing to daytime elevated nitrate in an urban atmosphere. Atmos. Environ. 186: 209-215. https://doi.org/10.1016/j.atmose nv.2018.05.040

Thunis, P., Clappier, A., Tarrason, L., Cuvelier, C., Monteiro, A., Pisoni, E., Wesseling, J., Belis, C. A., Pirovano, G., Janssen, S., Guerreiro, C. and Peduzzi, E. (2019). Source apportionment to support air quality planning: Strengths and weaknesses of existing approaches. Environ. Int. 130: 104825. https://doi.org/10.1016/j.envint.2019.05.019

Tian, M., Wang, H., Chen, Y., Zhang, L., Shi, G., Liu, Y., Yu, J., Zhai, C., Wang, J. and Yang, F. (2017). Highly 
time-resolved characterization of water-soluble inorganic ions in $\mathrm{PM}_{2.5}$ in a humid and acidic mega city in Sichuan Basin, China. Sci. Total Environ. 580: 224-234. https://doi.org/10.1016/j.scitotenv.2016.12.048

Wu, K., Yang, X., Chen, D., Gu, S., Lu, Y., Jiang, Q., Wang, K., Ou, Y., Qian, Y., Shao, P. and Lu, S. (2020). Estimation of biogenic VOC emissions and their corresponding impact on ozone and secondary organic aerosol formation in China. Atmos. Res. 231: 104656. https://doi.org/10.10 16/j.atmosres.2019.104656

Xing, J., Wang, J., Mathur, R., Wang, S., Sarwar, G., Pleim, J., Hogrefe, C., Zhang, Y., Jiang, J., Wong, D.C. and Hao, J. (2017). Impacts of aerosol direct effects on tropospheric ozone through changes in atmospheric dynamics and photolysis rates. Atmos. Chem. Phys. 17: 9869-9883. https://doi.org/10.5194/acp-17-9869-2017

Yang, X., Wu, K., Wang, H., Liu, Y., Gu, S., Lu, Y., Zhang, X., Hu, Y., Ou, Y., Wang, S. and Wang, Z. (2020). Summertime ozone pollution in Sichuan Basin, China: Meteorological conditions, sources and process analysis. Atmos. Environ. 226: 117392. https://doi.org/10.1016/j.at mosenv.2020.117392

Young, L.H., Li, C.H., Lin, M.Y., Hwang, B.F., Hsu, H.T., Chen, Y.C., Jung, C.R., Chen, K.C., Cheng, D.H., Wang, V.S., Chiang, H.C. and Tsai, P.J. (2016). Field performance of a semi-continuous monitor for ambient $\mathrm{PM}_{2.5}$ watersoluble inorganic ions and gases at a suburban site. Atmos. Environ. 144: 376-388. https://doi.org/10.1016/j.atmose nv.2016.08.062

Zhang, L., Guo, X., Zhao, T., Gong, S., Xu, X., Li, Y., Luo, L., Gui, K., Wang, H., Zheng, Y. and Yin, X. (2019). A modelling study of the terrain effects on haze pollution in the Sichuan Basin. Atmos. Environ. 196: 77-85. https://doi.org/10.1016/j.atmosenv.2018.10.007
Zhang, Y., Liu, Z., Lv, X., Zhang, Y. and Qian, J. (2016). Characteristics of the transport of a typical pollution event in the Chengdu area based on remote sensing data and numerical simulations. Atmosphere 7: 127. https://doi.org/ 10.3390/atmos7100127

Zhao, S., Yu, Y., Yin, D., Qin, D., He, J. and Dong, L. (2018). Spatial patterns and temporal variations of six criteria air pollutants during 2015 to 2017 in the city clusters of Sichuan Basin, China. Sci. Total Environ. 624: 540-557. https://doi.org/10.1016/j.scitotenv.2017.12.172

Zhao, S., Yu, Y., Qin, D., Yin, D., Dong, L. and He, J. (2019). Analyses of regional pollution and transportation of $\mathrm{PM}_{2.5}$ and ozone in the city clusters of Sichuan Basin, China. Atmos. Pollut. Res. 10: 374-385. https://doi.org/1 0.1016/j.apr.2018.08.014

Zheng, B., Zhang, Q., Zhang, Y., He, K.B., Wang, K., Zheng, G.J., Duan, F.K., Ma, Y.L. and Kimoto, T. (2015). Heterogeneous chemistry: A mechanism missing in current models to explain secondary inorganic aerosol formation during the January 2013 haze episode in North China. Atmos. Chem. Phys. 15: 2031-2049. https://doi.org/10.51 94/acp-15-2031-2015

Zheng, B., Tong, D., Li, M., Liu, F., Hong, C., Geng, G., Li, H., Li, X., Peng, L., Qi, J., Yan, L., Zhang, Y., Zhao, H., Zheng, Y., He, K. and Zhang, Q. (2018). Trends in China's anthropogenic emissions since 2010 as the consequence of clean air actions. Atmos. Chem. Phys. 18: 1409514111. https://doi.org/10.5194/acp-18-14095-2018

Received for review, April 25, 2020 Revised, September 7, 2020 Accepted, October 4, 2020 